\title{
Service Robotics in Construction
}

\author{
Bock Thomas \\ Technical University Munich \\ Germany
}

\section{Introduction}

The first service robots for construction had been developed end of seventies beginning of eighties of the last century in Japan. These early service robots were used in the construction sector for inspection of nuclear power plants, exterior walls of high rise buildings and cleaning of high rise facades or glass roofs.

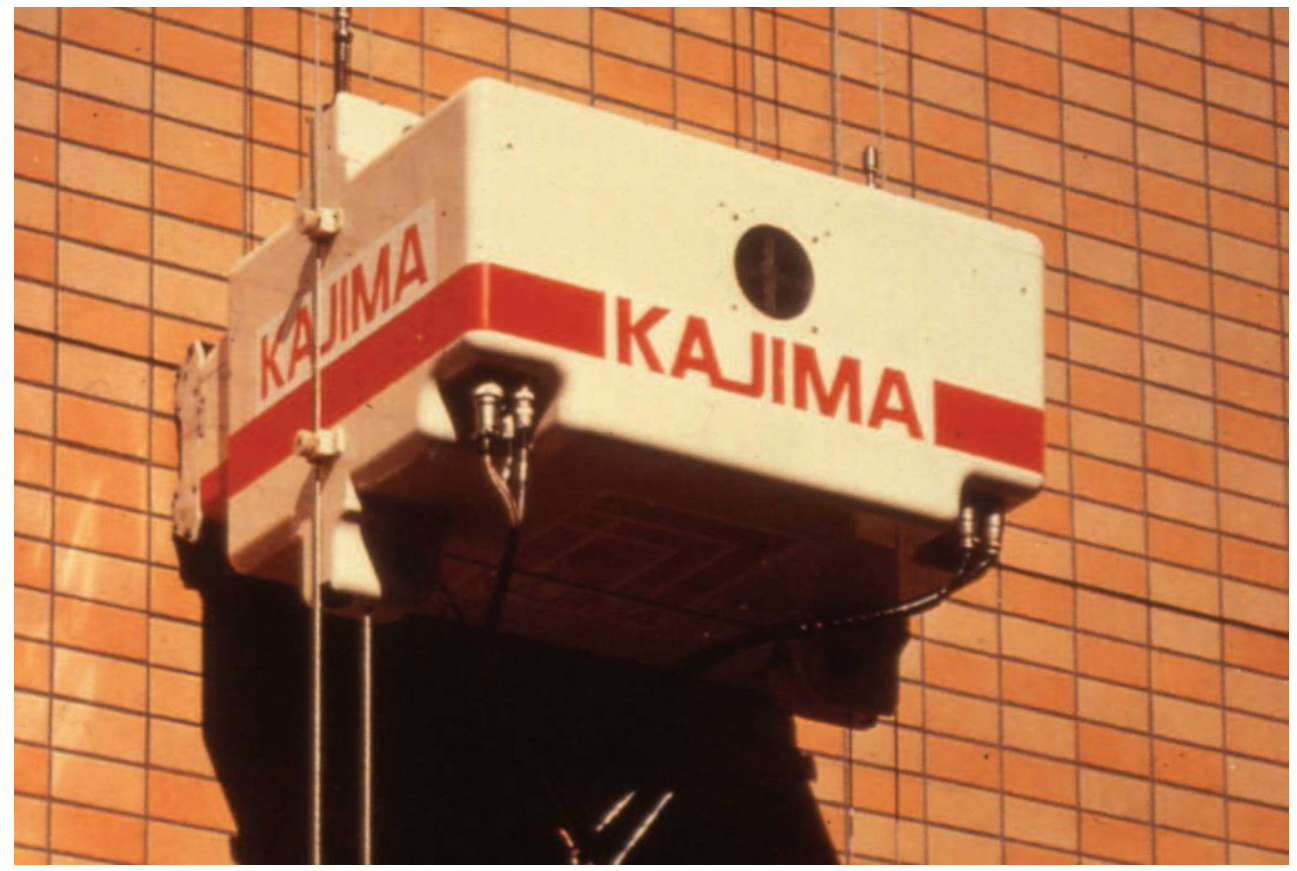

Fig.1 Kajima façade diagnostic robot

In the nineties service robots were applied to civil engineering projects such as inspection of tunnels, railroad tracks and bridges. 


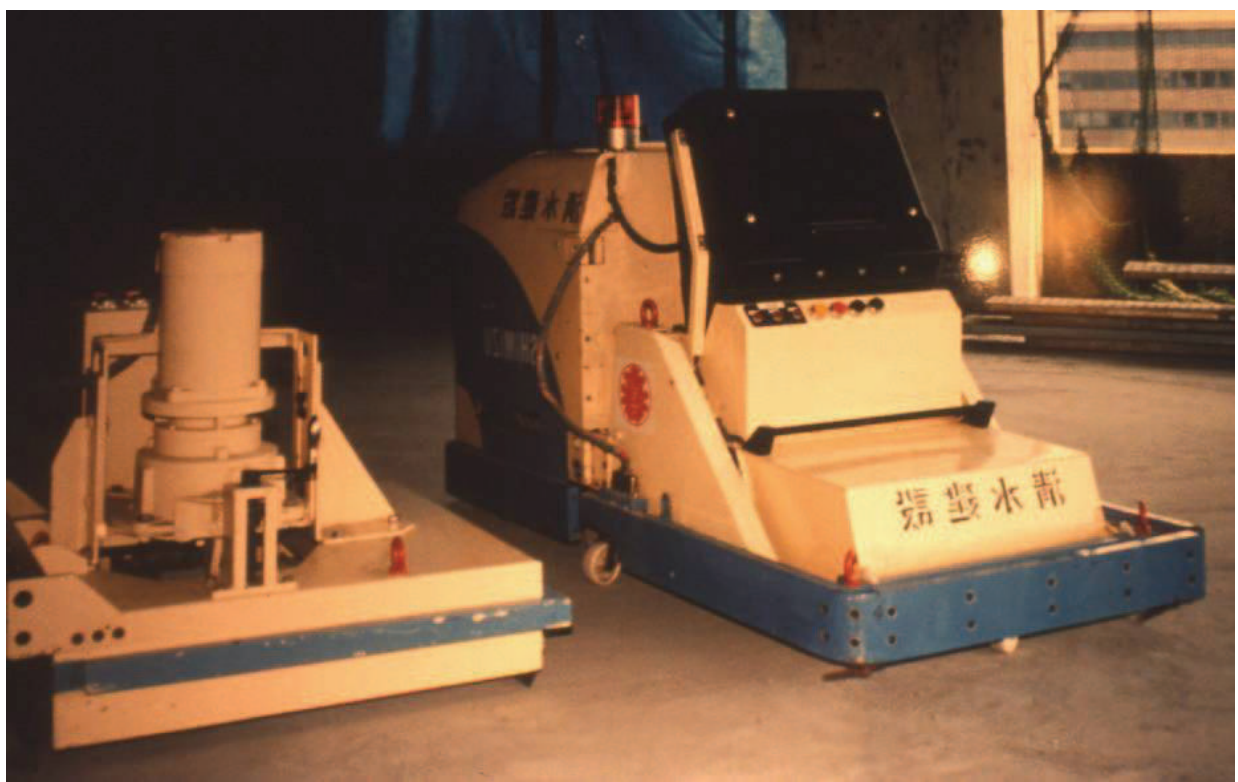

Fig. 2 MTV Cleaning robot

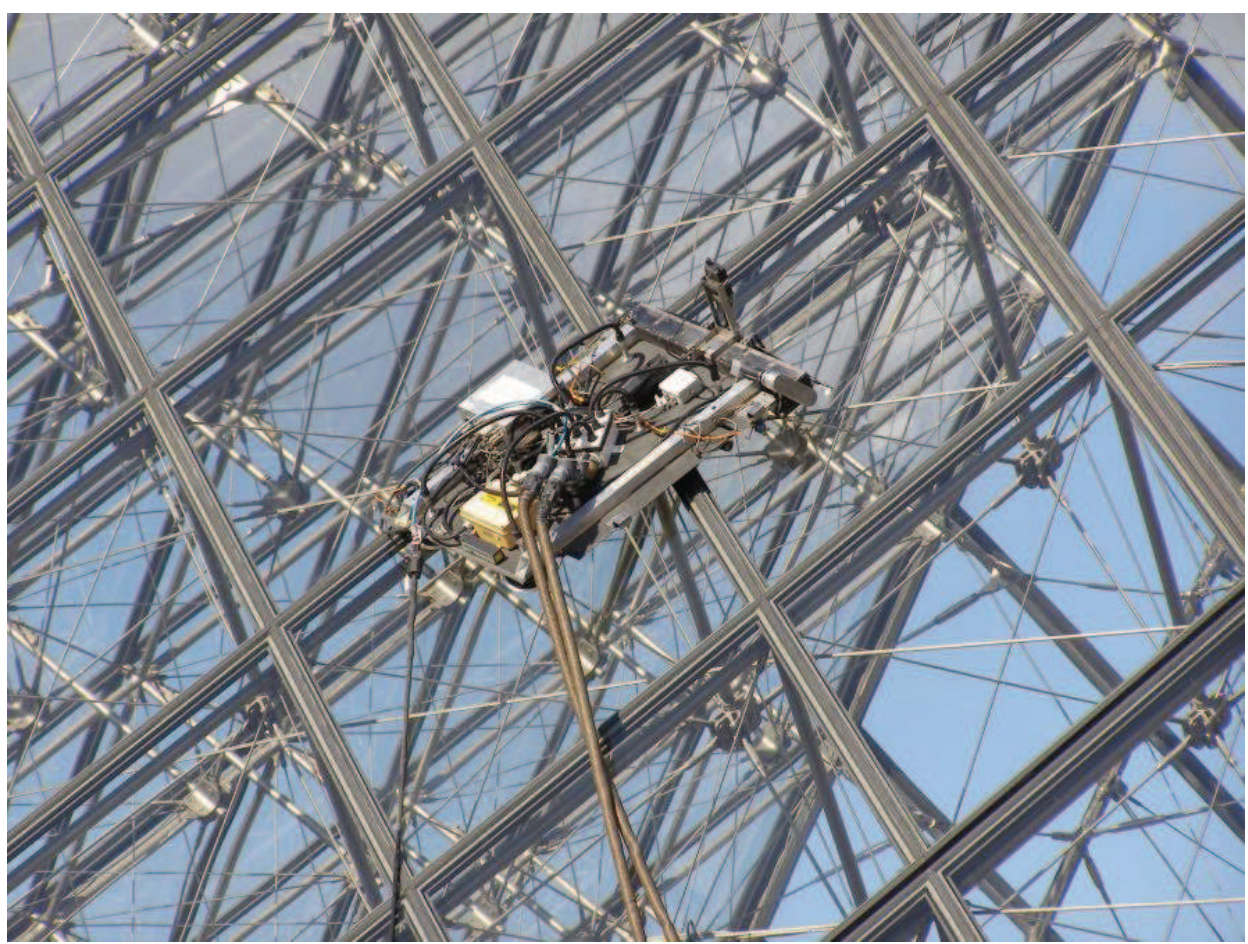

Fig. 3 Comatec robosoft glass cleaning robot 
Advances in the autonomous robotics research resulted in service robots for office logistics of files and security against intruders, gas leaks or fire hazards etc.

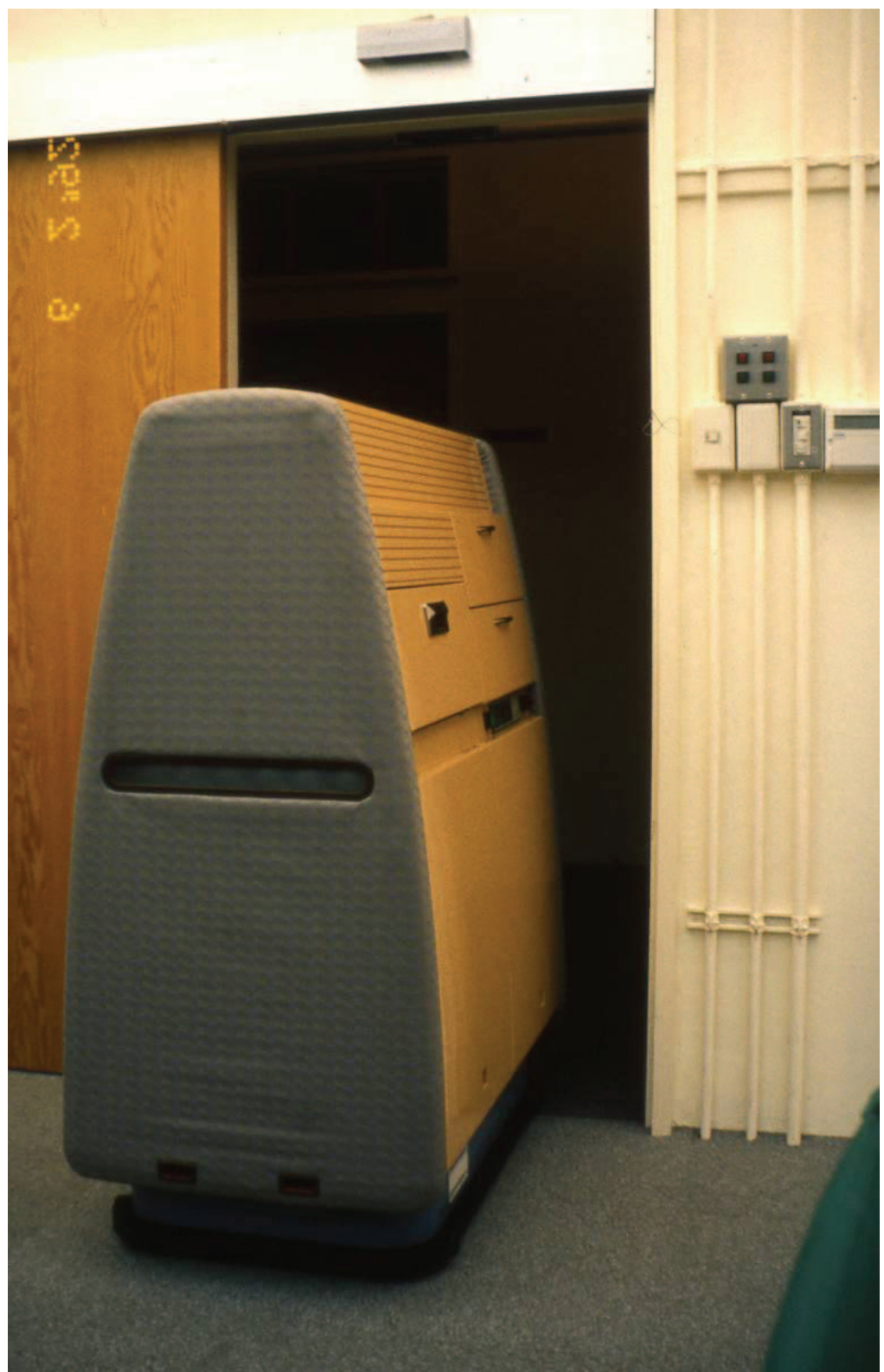

Fig. 4 Tron office service robot

Due to the demographic changes especially in Japan service robots are being developed as partner, pet or personal robots for day care centers, hospitals and apartments. 


\section{Information and communication technology for service robotics in buildings}

\subsection{Home automation}

Home automation systems are offered by all major electronic companies, such as Hitachi (home control system), Nihon Denki (Jema Home Bus), KEC (Kansai home bus system), Matsushita Denki Sangyo (Stavtec, Hals, HA system), Matsushita Denko (Napic Remote Control, Homen Mast, HA Installation System), MITI (MITI Home Bus), Mitsubishi Denki (House Keeping System, Home Automation System), MPT (HBS), NEC (Home Media Bus), NHK (Home Bus System), NTT (HAN), Sanyo Denki (Shains), Sharp (home Terminal System, House Info System, Home Bus System), Sony (Access 3), Toshiba (Nexhome Media System, Home Control System). In Europe Siemens Building Systems and Philips Home Lab and in USA Honeywell, Johnson Controls, Microsoft's "cyber home" in Medina and the Georgia Tech's Aware Home's Living room and MIT House conduct research by building real living environments

Major functions of standard installation cover fire alarm, gas leakage alarm (detection and notification), oxygen shortage alarm (detection and notification), electric lock (unlocking function, when a visitor is checked), burglar alarm (sensor notifies when a door or window is opened or broken), emergency alarm (notification to the public emergency center), earthquake alarm (notification of an inherent earthquake while switching appliances to appropriate mode), guest monitor at door, interphone between rooms, doorphone, power control, HVAC (heating-ventilation-air conditioning) control and control of water level and temperature of bathtub. As an example of home automation follow as a brief outline of Mitsubishi Melon home automation system.

Mitsubishi Electric thinks of home automation as information oriented home management. Center piece is the "in house total information system." The next level is formed by "household control systems" and "lifestyle information utilization system". On the third level we find "house keeping", "home management", and "life-culture".

Last level consists of "fire and crime prevention", "Energy control", "environmental and equipment control", "Data communications", "health care", "education and training ", "bussiness and culture" and "hobbies and entertainment".

This means that home medical care, home banking, home shopping, at home ticket reservation, at home employment, electronic mail, home nursing, home study, tele-controlmonitoring-metering can be done without leaving home.

\subsection{TRON house projects and Toyota personal robotics business model}

This project supported by the Ministry of international trade and industry developped a new kind of computer chip. For international communication an automatic translation system was developed. With the help of TRON (Tron realtime operating nucleus) by Prof. Ken Sakamura of University of Tokyo, information and communication technology, intelligent robots should enable aged people and handicapped people in independant daily life.

The Tron project was started in 1979. In 1981, a committee was set up to envision the information society of the 90 's and the requirements of the future computer technology needed for the social development on all levels and with regard to all aspects.

This project supported by the Ministry of international trade and industry aimed at developing a new kind of computer. With the help of the fifth generation computer technology, intelligent robots should support elderly and handicapped people in their daily life. 


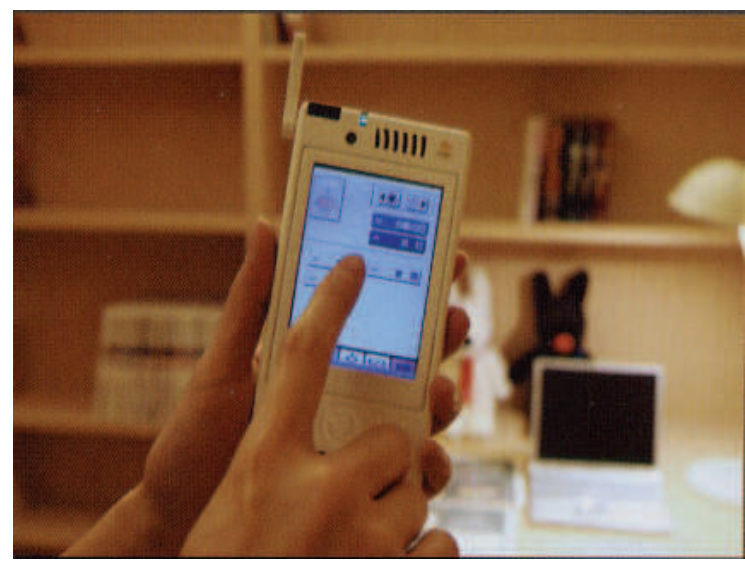

Fig. 5 Tron ubiquitous controller

The goal of the TRON Project has always been to create of a total "computer architecture", so it would be possible to establish a computer-based society in the $21^{\text {st }}$ century. The "TRON Intelligent house" was one of the many TRON application projects that was actually built. The core of the concept was the symbiotic fusion of nature, humans and computers. It was completed in 1989 in Nishi Azabu for a price ticket of 1 billion yen or roughly 7 million $€$.

At that time, the intelligent house was the most computerized building, with 380 computers interconnected via the TRON architecture. While these computers were able to control every window or door, television, security system, and even the kitchen appliances remotely and automatically, the building itself and the major amenities were made of traditional Japanese wood material - thus combining Japanese computer technology with the traditional aspects of domestic architecture. Nowadays, many of these appliances are considered standard or helpful - especially considering the demographic changes in some countries.

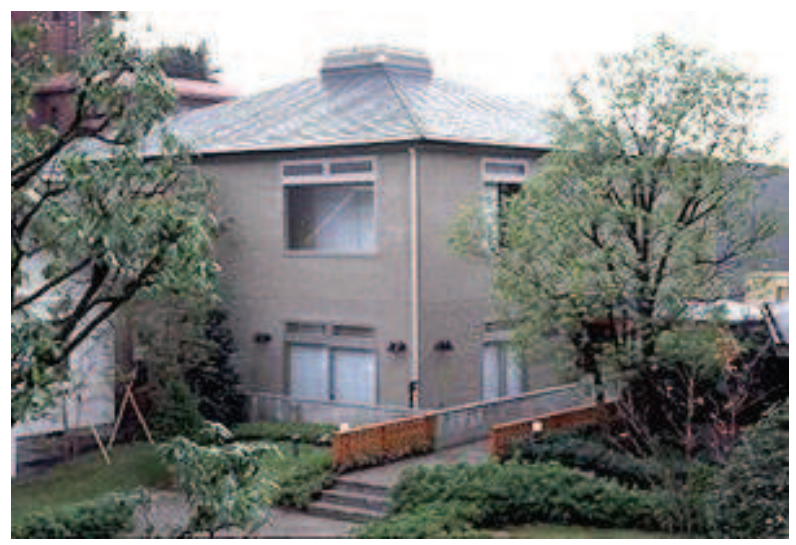

Fig. 6 Tron House Nishi Azabu

In 2005 Toyota Home K.K. has developed a new intelligent home, based on TRON and other leading edge technologies. The house is called "Toyota Dream House PAPI." It is a smart or intelligent home and was created to reflect the all-purpose computing technologies that will be available for intelligent home construction in the year 2010. 
Toyota Home creates modules to construct homes in factories that are similar to automobile businesses. With this application, Toyota demands that Prof. Sakamura learns about modular home construction techniques and adapts his design accordingly. That is why the company fully intends to bring the technologies on the market after they become commercially feasible. The main objective of this project was to create and realize an environmentally friendly, energy saving, intelligent house design in which the latest network computing technologies developed by the T-Engine project could be tested and further developed.

The total area of the house is 689 square meters. The house is mainly made of recyclable materials such as glass and aluminium. There is no need to clean the large glass windows regularly because of a special self-cleaning coating. In addition, Toyota Dream House PAPI possesses the technology along the lines of TRON to secure communication between the nodes. Nano T-Engine and pico T-Engine are used to make the construction of the nodes easy. The respective network is fairly sophisticated and the Toyota personal robot uses this network for navigation.

This personal robot among I-Foot, I-Unit and I-Real indicates the future business model of Toyota motor corporation for 2020 when the core business will shift from cars to personal robots. The Ubiquitous Communicator (UC) identifies people moving through the computerized living space and their personal preferences can be recognized. Though, the $\mathrm{UC}$ is only one of many HMIs, which can be used in the Toyota

\section{Health care technologies for service robots in day care centers, hospitals and at home}

\subsection{Patient robots}

While industrial robots perform the role of producing something, medical robots are simulators that play a passive role, and are used in educational programs for physicians and nurses. These medical robots are called patient simulators.

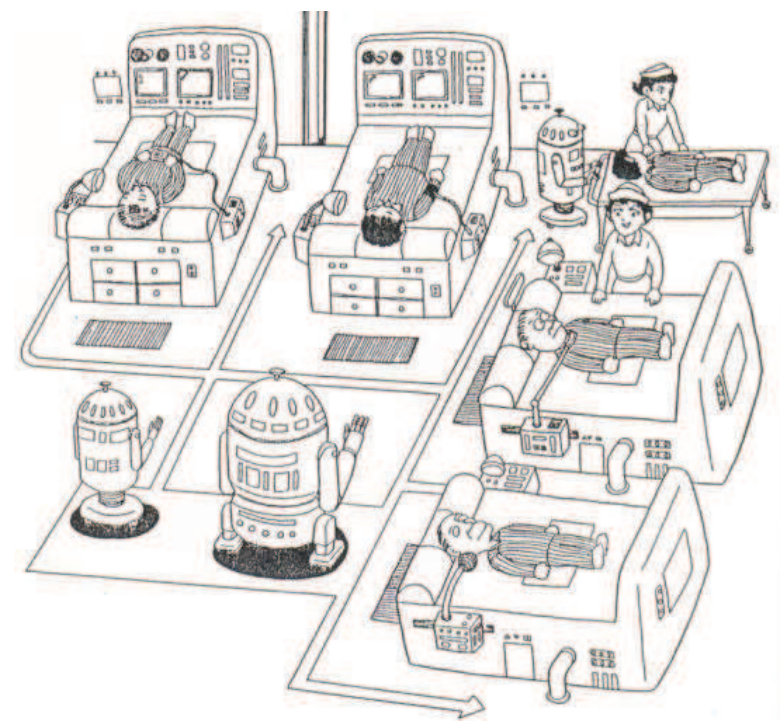

Fig. 7 Japan Science Society 1986 
There is another type of simulator robot, called a dummy robot, which is placed in a car to collect data on the possible damage which human passengers might suffer in an accident of automobile collision. The patient robot shares the same concept.

The first patient robot in USA was an education robot for anaesthesia developed by the University of Southern California. Called SIM-1 (meaning simulator No. 1), this robot was designed for use as an educational model to show young physicians and nurses how anaesthesia should be administered to patients before surgery.

First, the condition of a patient and the surgery to be performed are shown to the students, who then determine the kind of anaesthesia to be administered to the patient. When an action corresponding to administering anaesthesia is taken, the robot that is connected to a computer reacts to the anaesthesia, showing a rise in the palpitation of the heart or a rough breath. The computer outputs the data which show whether the action that has just been taken is correct. The simulator robot also shows change in blood pressure, reaction of the pupil, etc. and, if an intravenous drip injection is administered, allows monitoring of the reaction of a living body. Patient simulators for the blood circulatory system were also developed in the United States.

In Japan, a training robot for bringing drowned persons to life again was developed by a group of Tokyo Women's Medical College. The robot has reactive mechanisms responding to a heart massage or mouth-to-mouth breath, showing restoration to the normal pulse and normal blood pressure, or to normal reaction of the pupil, or to a regular heart beat. This robot is also connected to a computer to give data in numerical values.

The monitor displays the condition of the patient and the instructions to the students, such as "Blood not circulating enough," "Massage more correctly," and "Breath not enough." The training results can be confirmed again with recordings on paper. Other robots train dentists etc.

\subsection{Medical diagnostic robots in buildings}

Robots are also being used for medical diagnostic purposes. Apart from many electromechanical devices, such as CT scanners and ultrasonic appliances, that are used as auxiliary tools of diagnosis, diagnostic robots and wearable medical diagnostic devices scanning pulse, oxygen etc. using UMTS, WLAN or blue tooth are emerging.

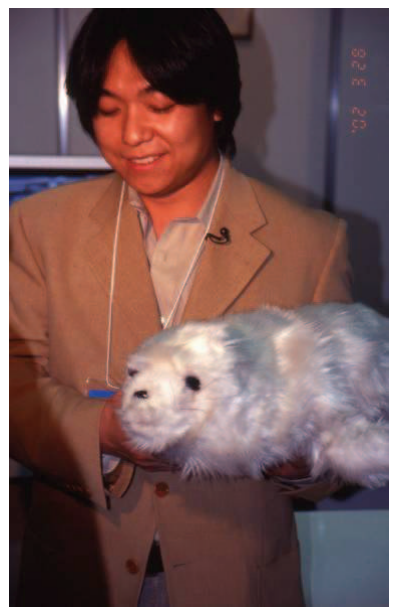

Fig. 8 Paro therapeutic robot 
The present robots for industrial use perform work only on hardware, that is materials and machines. But robots will then be able to work on not only hardware but also human beings. One of the fields where such robots will be usable is medicine. Another is rehabilitation. Service robots will also be used at home to help sick or old people. The technique of the breast cancer diagnostic robot will be basic and important, opening the way to application to one field after another. It will provide basic know-how for developing what may be called a home robot or a personal robot which will be used at home to help sick or old people.

This diagnostic robot has nearly reached the level of practical usefulness. The technique of this robot that has been developed so far carries an important meaning as a basic technique to develop artificial senses close to those of the human being, which future robots must have.

\subsection{Pet robots}

Pet robots which will directly help the sick are being developed.

Patients who have just been operated on and old sick persons who have to stay in bed need the help of someone else. The illness may cause any change in their physical condition or raise physiological needs anytime. So, someone must always be there to help the patient. The fact, however, is that this kind of service is getting increasingly difficult to expect. There are anticipations, therefore, that tender robots will be available to help patients and sick old persons.

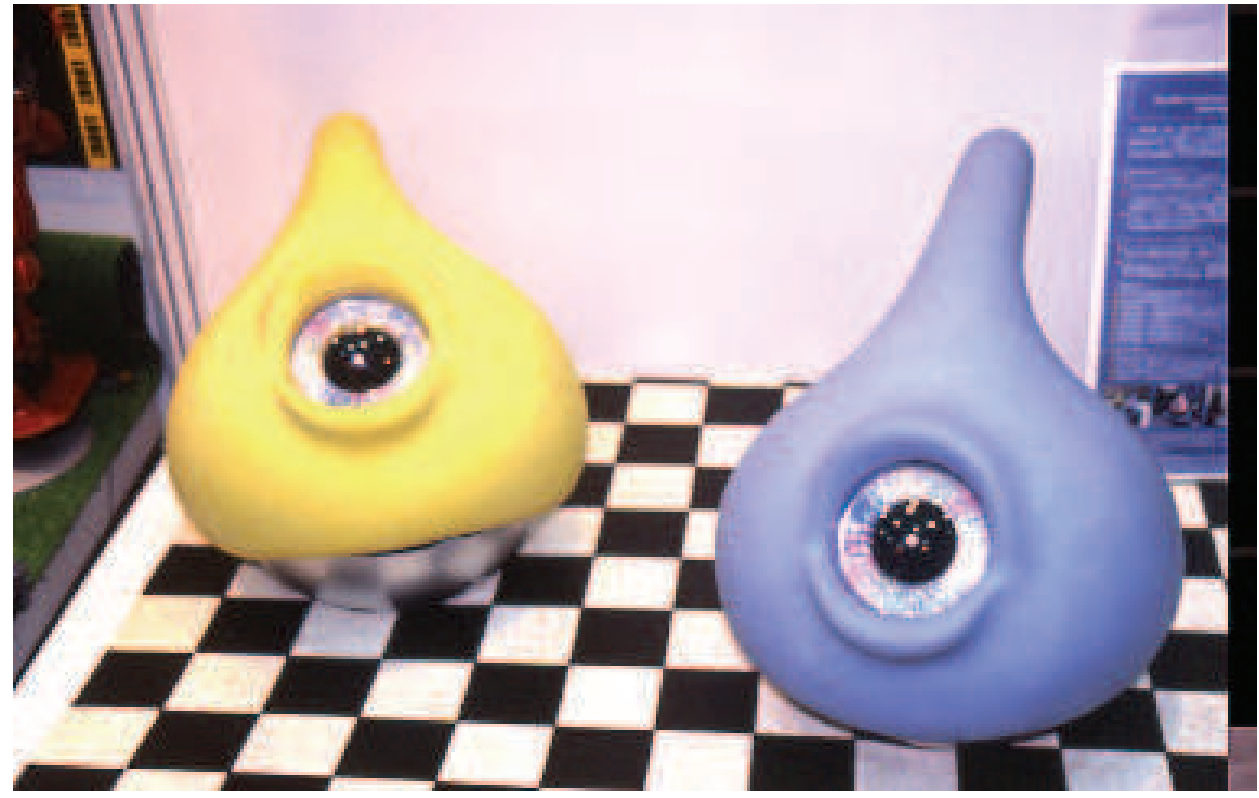

Fig.9 Pet Robot

Medical pet robots may be required to have functions similar to those of ordinary industrial robots in some cases. To help a sick person lying in bed drinking something, for example, the robot needs to handle only hardware, that is, a glass. That kind of technique has already been developed for industrial robots. 
When it comes to do something more complex, however, problems may occur. For example, a person lying in bed may have to be taken up in the arms from the bed and moved to a wheelchair. Or, a sick person may need help in taking a bath. In such cases, a human helper carefully holds and helps the sick one making full use of the senses of the skin. If a robot tries to do it with its hard mechanical hands, the sick person could be injured.

Therefore, robots for these purposes must have senses similar to those of the human skin, which the breast cancer diagnostic robot has in the form of artificial fingers.

Another system uses a cushion and extends two arms under it to hold a patient up.

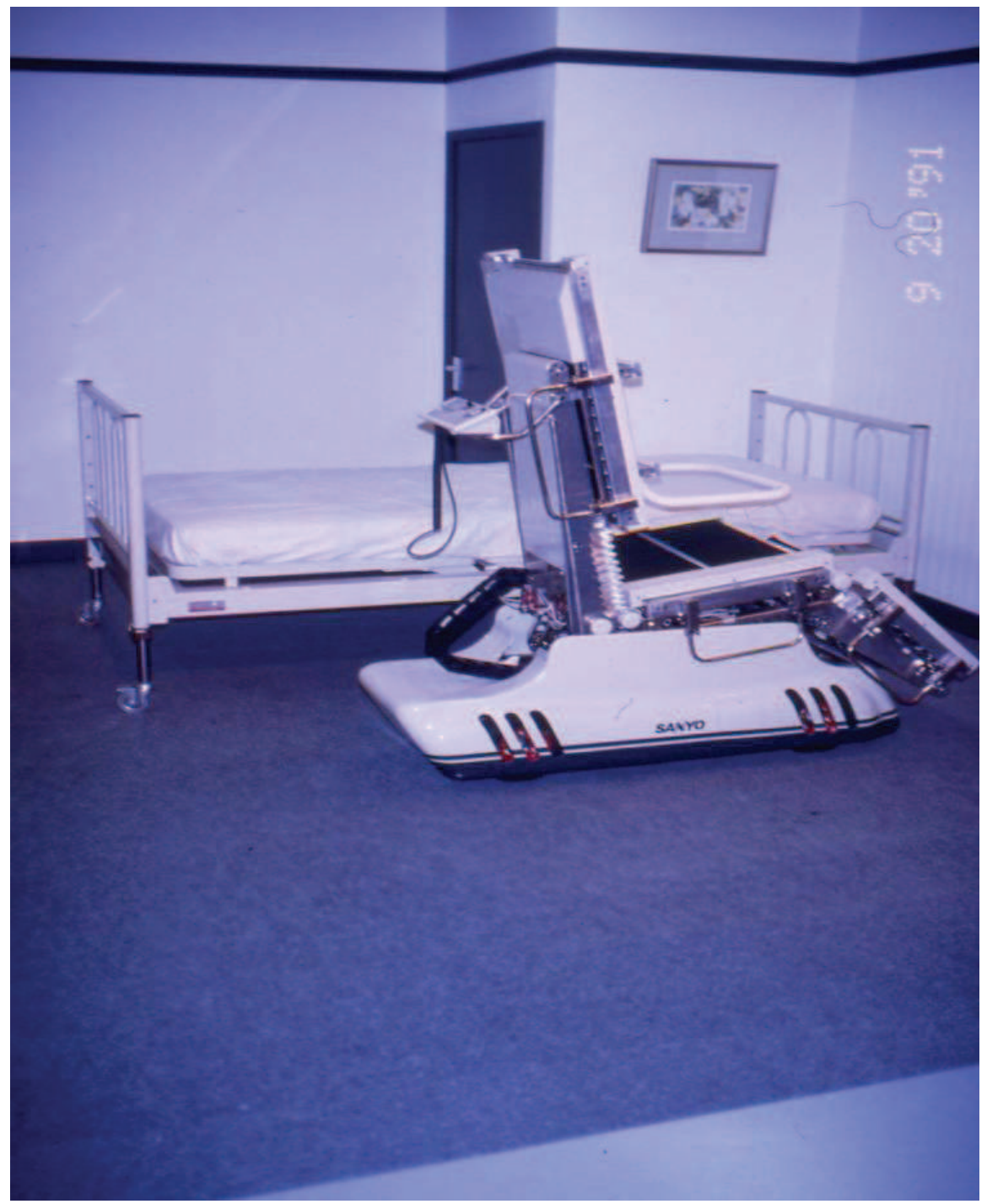

Fig. 10 Sanyo robotic patient transfer and wheelchair System 


\subsection{Assistive robots}

Attention is paid to robots which will help physically handicapped people in many ways. Guide dogs, for example, help those who cannot see. A guide robot to substitute guide dogs is being developed. It is a system which transmits information as signals by electric stimulation from an electrode box, to be hand-held by a visually handicapped person, to guide him or her.

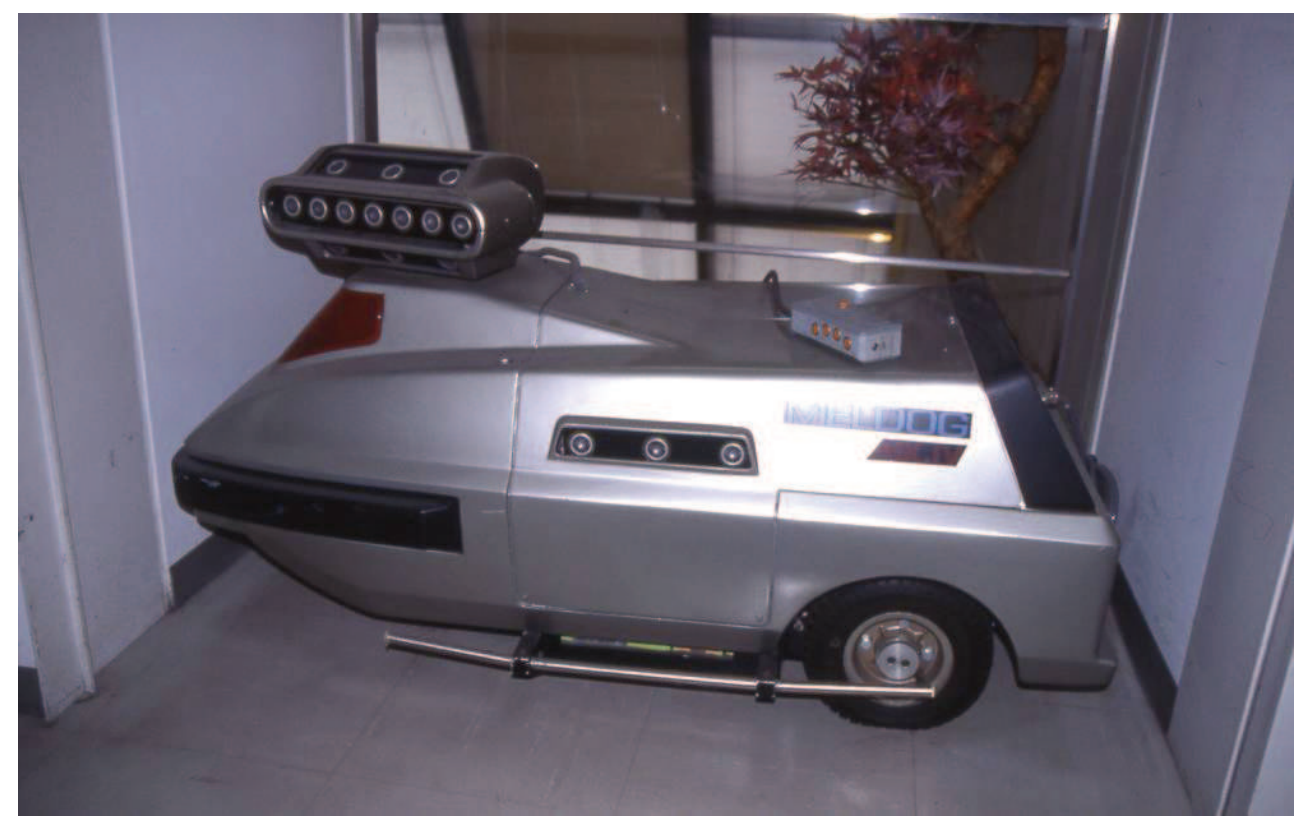

Fig. 11 Mel Dog , Prof. S. Tachi, Mechanical Engineering Laboratory , MITI, Japan

A mechatronic walking device was developed for disabled persons. Later manipulators will be added to enhance performance and future robot technology is also applied to artificial hands and legs for those who lost them. Artificial hands and legs of an electromyogram controlled system now available can be used in the same way as human hands and legs. As a command is transmitted from the brains via the motor nerves to the muscles, the muscles contract to move the hands or legs. Artificial hands and legs of the electromyogram controlled system are based on the same theory.

An electrode is placed on the skin of a limb extremity to receive a command transmitted via the motor nerves. The command is interpreted by a small electronic circuit - a kind of computer - and the artificial hands or legs are driven according to the meaning of the electronic signal deciphered.

Some robots have sensing device in an artificial hand. The human hands and legs have coetaneous sensation, and feed back information on the objects they touch via the sensory nerves to the brains. These robots work in a similar way. When the artificial hand touches something, the sensing device built in the hand converts the information into electrical signals to be transmitted via the electrode placed on the skin at the extremity of the hand to 
the sensory nerves and to the brains, where a decision is made according to the electrical signals received. Different from the conventional type of artificial hand which opens or closes the fingers using the force of body muscles, this type of artificial hand can be directly used almost in a natural way without long training.

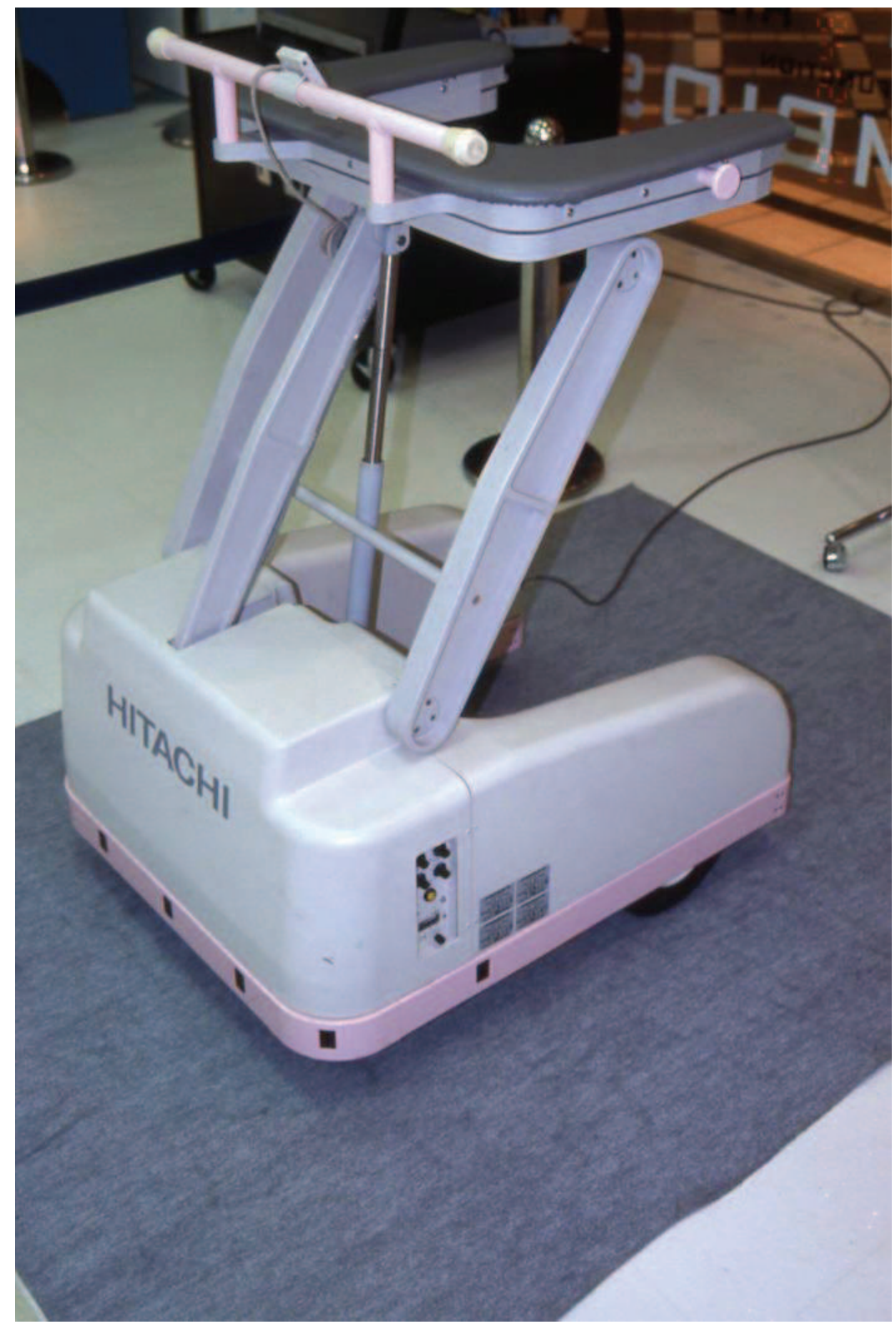

Fig. 12 Hitachi walking device 
If this electromyogram controlled system is applied to an artificial leg, walking speed can be automatically changed, or a stairway may be walked up or down using the artificial leg and the natural leg alternately - in the same way non-handicapped persons do.

This kind of system requires large power. One system uses a device of generating and storing power, implanted in the ankle of an artificial leg. When the wearer walks, the device generates energy from the rotary motion of the ankle in the walking direction, and stores that energy to drive the knee.

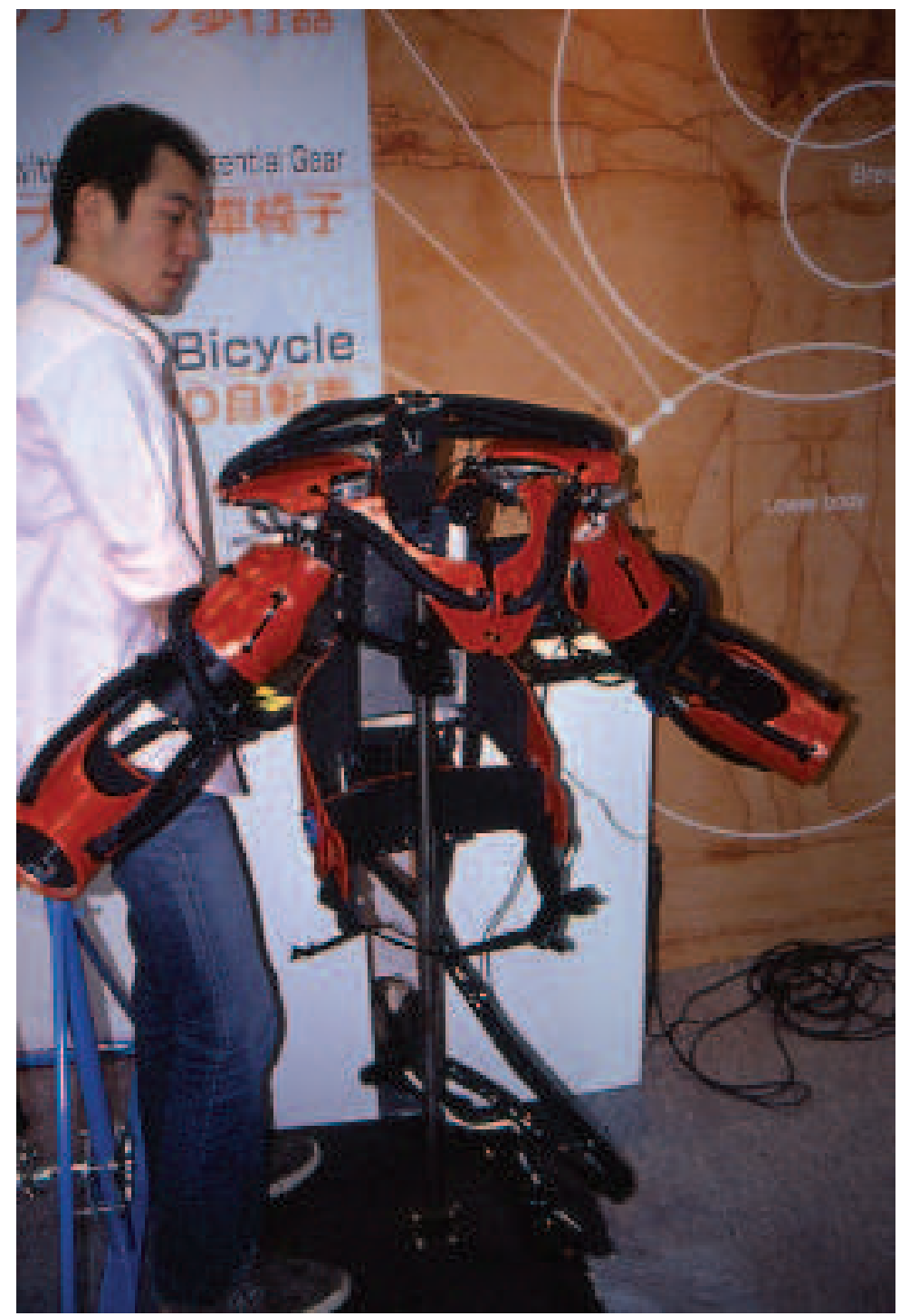

Fig. 13 Rika University, Tokyo 


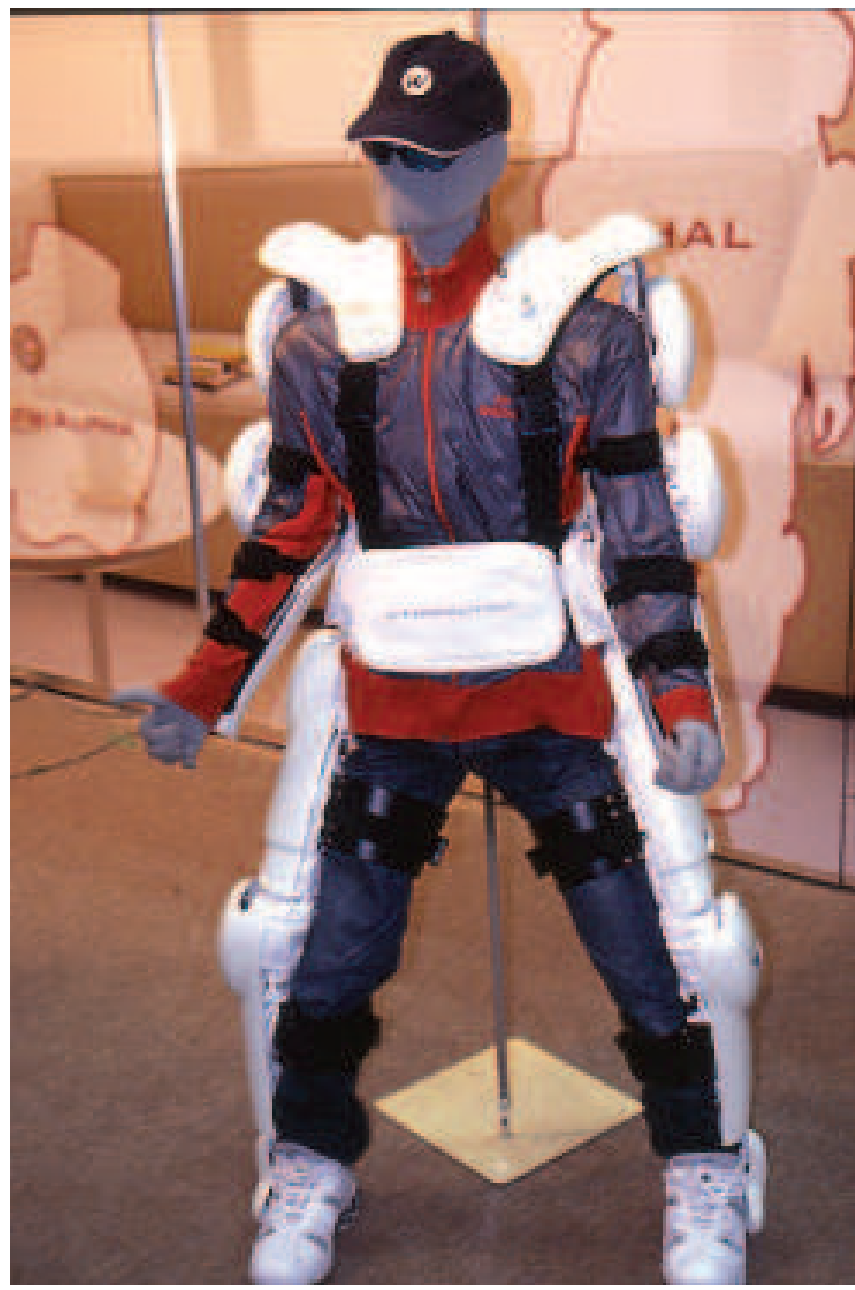

Fig. 14 HAL, Prof. Sankai, Tsukuba University

\subsection{Service robots in hospitals and health care centers}

Robotic techniques, computers and sensors assist and handle patients with sensory handicaps and support doctors with up-to-date computer-aided diagnosis. The pioneering work in this area was conducted by MITI in Japan at the Mechanical Engineering Laboratory (MEL). Here, the feasibility of a patient-handling robot, called "Nursy" was put to test. In addition, a multidirectional platform was developed with the potential use as a wheelchair for the disabled. Nursing costs and wages are steadily increasing. There is also a constant lack of nurses. Robots could perform some of these tasks in the future.

Repetitive hospital functions, such as delivering linens, preparing beds, giving medication, transporting patients, monitoring vital signs, supplying the patients with water and food are being automated. 


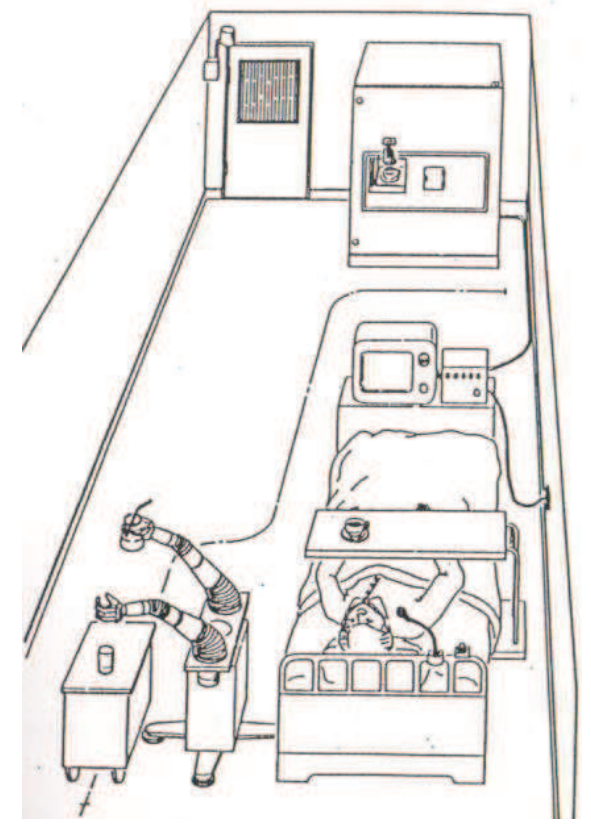

Fig. 15 Japan Science Society 1986

\section{LIESE: LIfE Support systEm: mechatronic renovation of building stock for independent life style of elderly}

To realize the "LIESE" concept in existing building stock, components were newly developed. Wooden wall finish component with handrail-shaped edge it functions as a handrail at a $75 \mathrm{~cm}$ level with incorporated RFID tags to detect position.

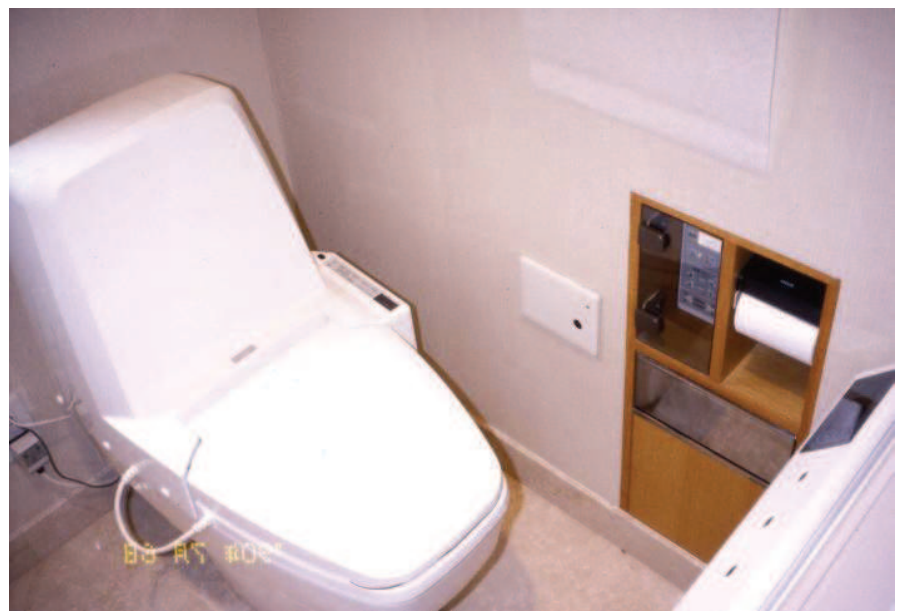

Fig. 16 Diagnostic toilet 
Flexible wall with a handrail-shaped edge: this is the wall that separates a room and a bathroom and can easily be disassembled.
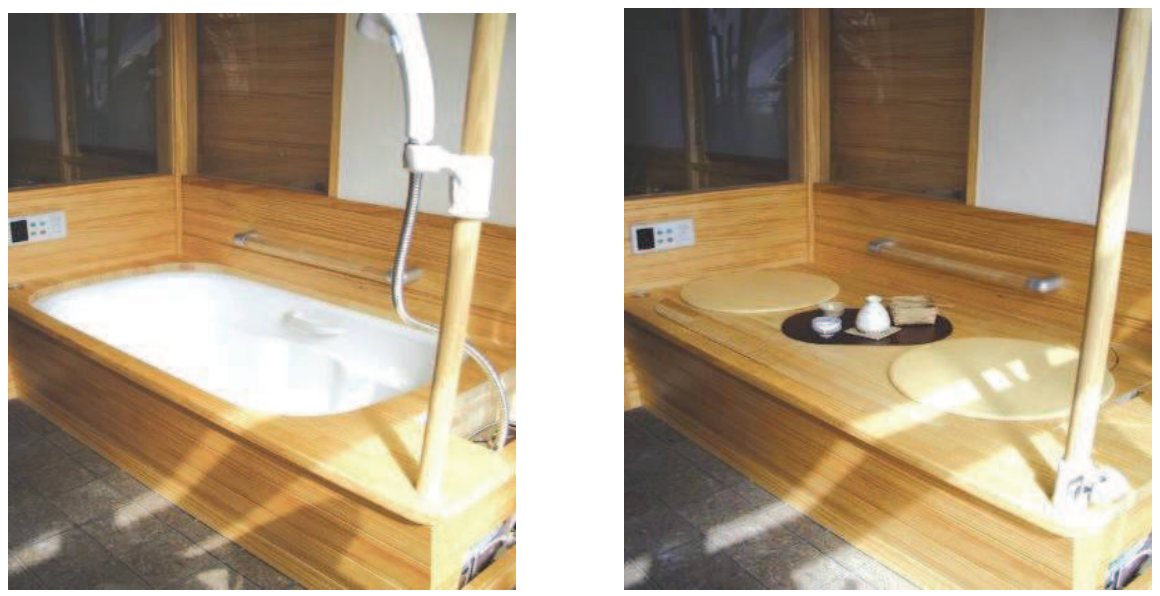

Fig. 17, 18 transformable bath tub

One direction movable bed with inbuilt servo motors which can easily move to support necessary care activities.

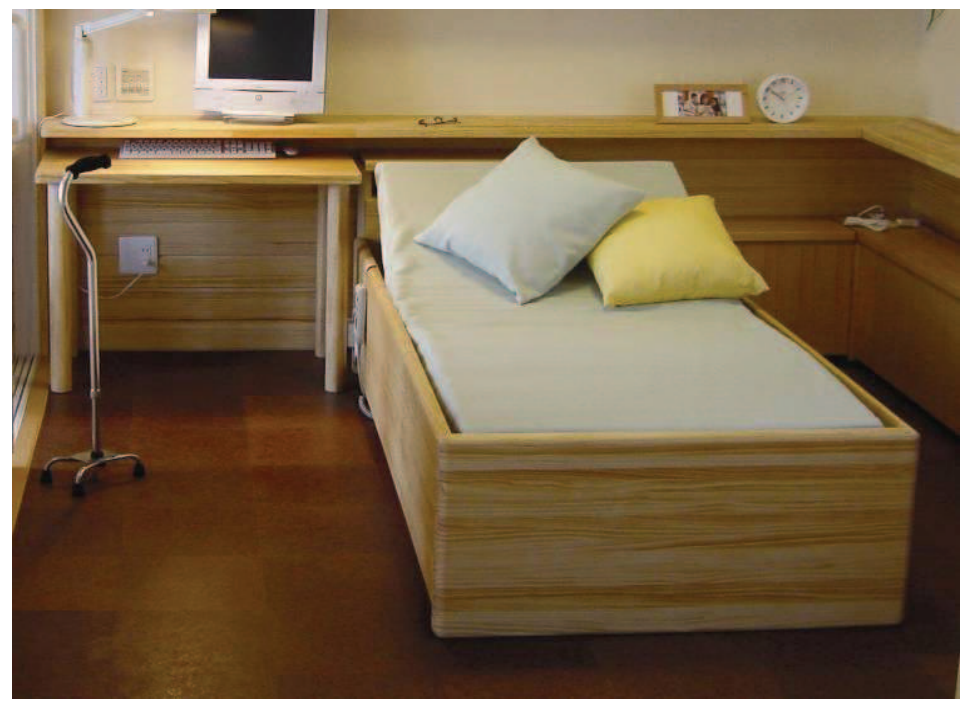

Fig. 19 Servo driven bed

Sliding door with a handrail-shaped edge: it has the function of stopping the door when one pushes the handrail-shaped edge downwards by installing the wheels equipped with the stop function below the door and easily supports the opening due to incorporated servo motor that detects the horizontal motion and assists the sliding of the door which is especially helpful while sitting in a wheelchair 


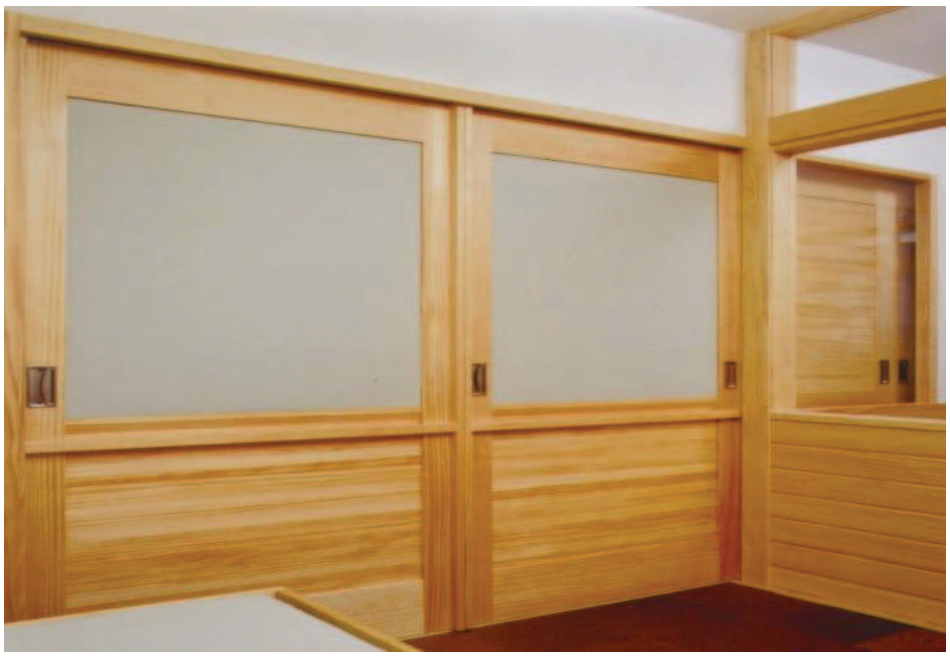

Fig. 22 Servo driven sliding door

Pumping toilet covered with table: it is covered with a movable table to conceal the toilet, and the pressure pump is used for its drainage. It is supposed that one lays a pipe for water supply and drainage using a bathroom that is in the center of the house, and a method involving a pressure pump is used in order to minimize the height of the raised floor at 15 $\mathrm{cm}$.
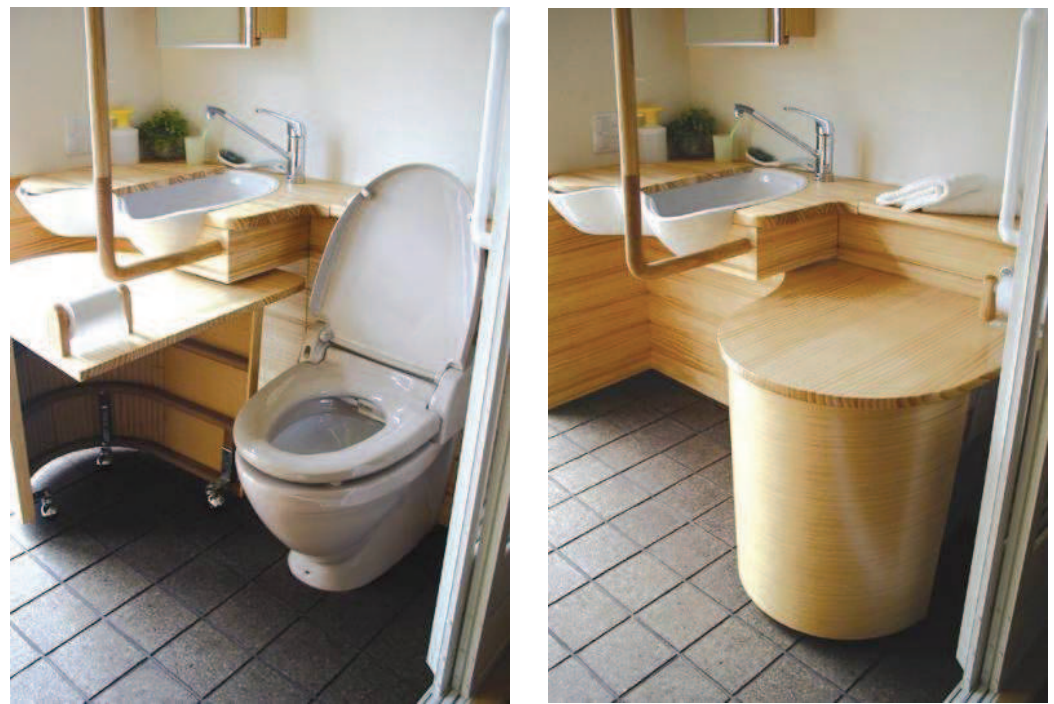

Fig. 20 , 21 Multi purpose toilet

The sensor floor panel features an inbuilt senor mat that detects fallen person. A waterproof sheet with synthetic rubber and plastic sensor sheet is placed on the floor with a waterproof panel on top of it. 


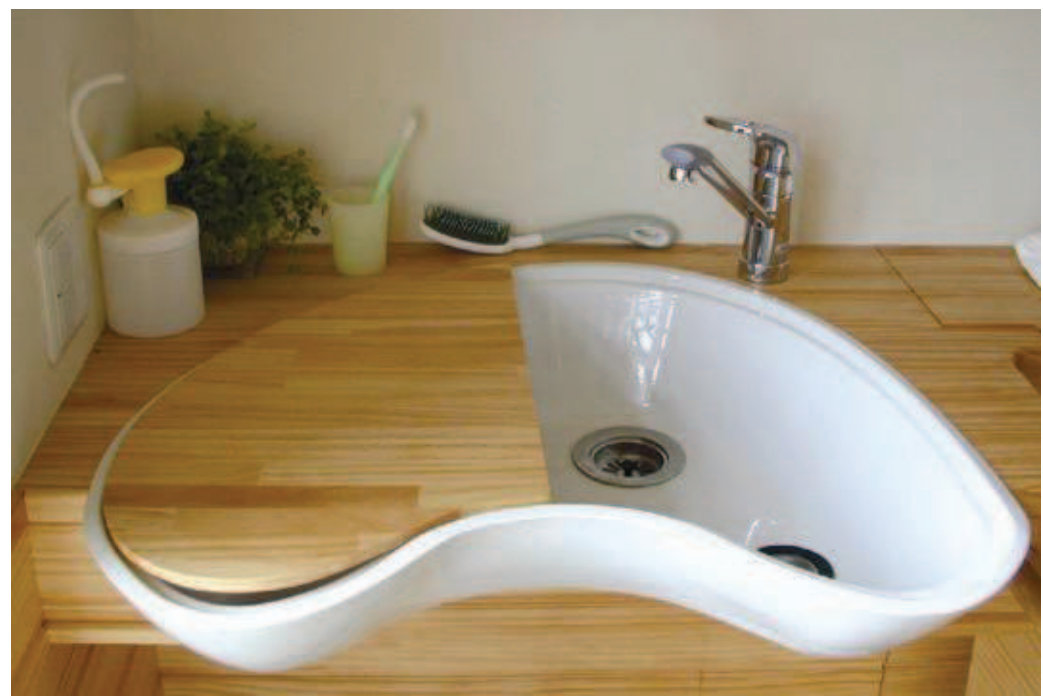

Fig. 23 Multipurpose sink

Multipurpose kitchen sink and washbowl can be installed in a narrow space and used as a small kitchen sink in some cases and as a washbowl in other cases. For this purpose, the shape of the sink is uniquely designed to correspond to both functions. The sink bottom is flat for kitchen use and it is deep enough for washing one's face. The sink has an asymmetric shape and allows comfortable approach by wheelchair. A new process of robotic metal shaping was successfully used to produce individually adjusted multipurpose sinks.

The bathtub can be transformed into a bench, when the tub is not in use and the shower can also be hidden.

\section{Future robotic technology for service applications in buildings}

Existing robotic technologies are based on industrial robotics application mostly for the production of cars and other mass production items. These industrial applications of robots require high speed motion, high accuracy and extended mean time between failure among other requirements. In the case of service robots for construction and building sector we need light weight robots with great payload and intuitive programming. Some of these technologies are available for example in space robotics such as the rotex light weight robotic arm developed by Professor Hirzinger.

\section{Future trends towards urban service robotics}

The next step according to Prof. Hasegawa in Japan will be the development of urban service robotics in which advanced robotic technology merge with architecture, buildings and urban infrastructure. The environment of human daily life is ill defined and dynamically changing in three spatial dimensions and time. Persons walk and drive around, layout of floor plans in buildings and furniture change so that any map, parametric world model facility management plans or building information models become obsolete. 


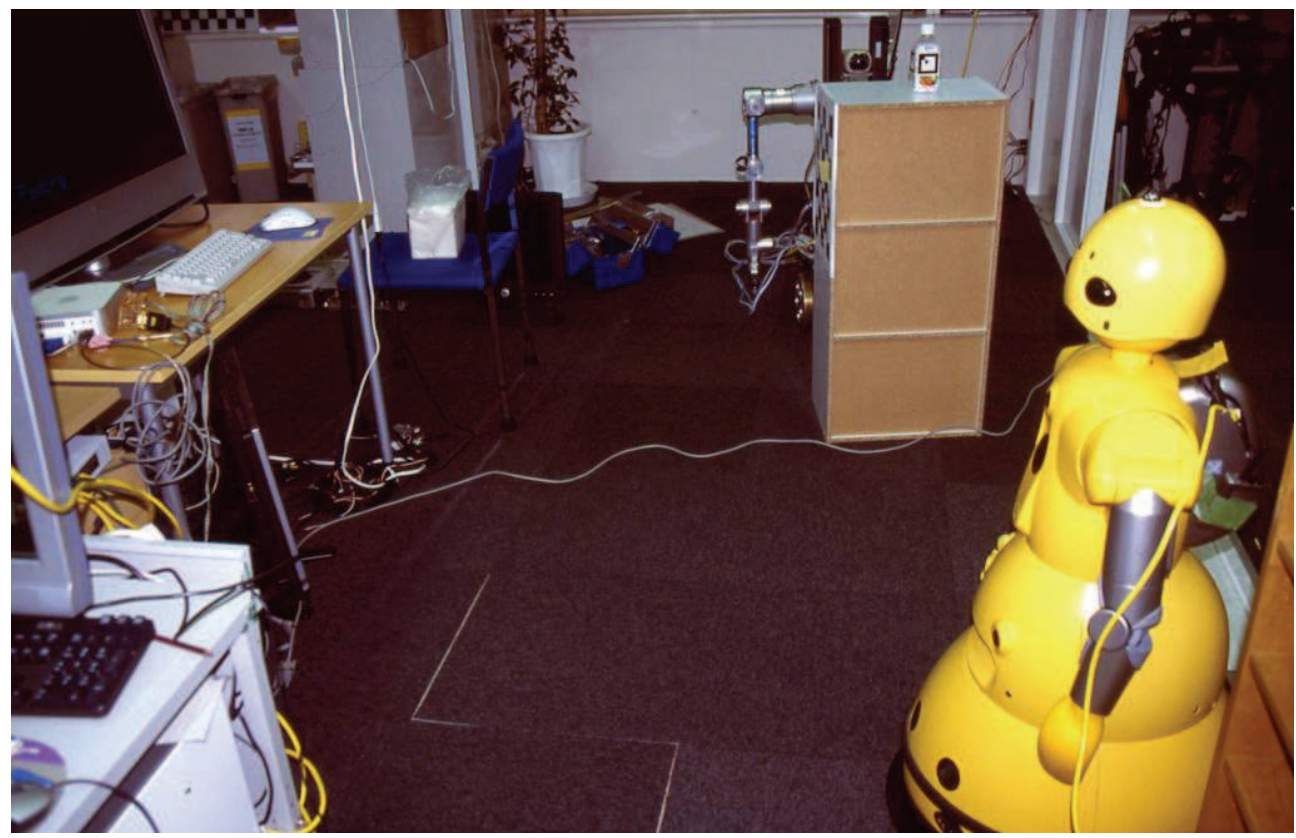

Fig. 24 Service robotics room at University of Tokyo, Prof. T. Sato and "Wakamaru" MHI

What is easy to recognize for humans is difficult to be realized by even advanced autonomous robots. Therefore the next step towards will be a structured environment using sensor network, vision systems, microwave and embedded distributed RFID tags and additional GPS for outdoors navigation.

\section{Conclusion}

Service robots in construction move from cleaning of the construction site and diagnosing of the building façade as security, logistic and assistive robots into the building and apartment and will in the future share urban environment with humans.

\section{References}

Matsumura S. ; Ando M, Ishizuka K., Kobata S., Seki E., Kumagai R., Development of the Renovation Technology of the Existing Residence for Elderly People, Journal of Architecture and Building Science, Vol.117 No.1498, pp.231-234, 2002

Matsumura S. ; "RAKU-INKYO” Infill System-upgrading existing dwellings for the elderly, Open House International, Vol.27, No.2, pp.64-68, 2002

Hasegawa T, ; Murakami K; Robot Town Project: Supporting Robots in an Environment with its Structured Information, pp.119-123, 3rd URAI, 2006

Bock T., Rojin Oriented Design for Life Support System, 6th BAS, Gits, Belgium, 2006 


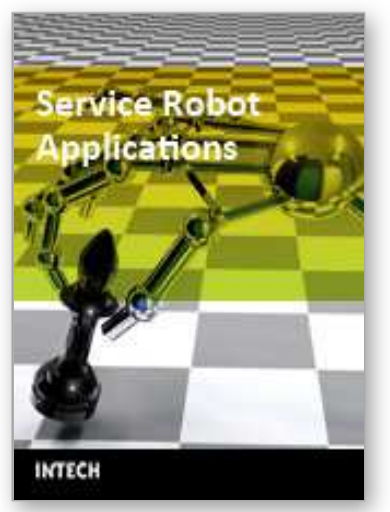

\author{
Service Robot Applications \\ Edited by Yoshihiko Takahashi
}

ISBN 978-953-7619-00-8

Hard cover, 400 pages

Publisher InTech

Published online 01, August, 2008

Published in print edition August, 2008

The aim of this book is to provide new ideas, original results and practical experiences regarding service robotics. This book provides only a small example of this research activity, but it covers a great deal of what has been done in the field recently. Furthermore, it works as a valuable resource for researchers interested in this field.

\title{
How to reference
}

In order to correctly reference this scholarly work, feel free to copy and paste the following:

Bock Thomas (2008). Service Robotics in Construction, Service Robot Applications, Yoshihiko Takahashi (Ed.), ISBN: 978-953-7619-00-8, InTech, Available from:

http://www.intechopen.com/books/service_robot_applications/service_robotics_in_construction

\section{INTECH}

open science | open minds

\section{InTech Europe}

University Campus STeP Ri

Slavka Krautzeka 83/A

51000 Rijeka, Croatia

Phone: +385 (51) 770447

Fax: +385 (51) 686166

www.intechopen.com

\section{InTech China}

Unit 405, Office Block, Hotel Equatorial Shanghai

No.65, Yan An Road (West), Shanghai, 200040, China

中国上海市延安西路65号上海国际贵都大饭店办公楼405单元

Phone: +86-21-62489820

Fax: $+86-21-62489821$ 
(C) 2008 The Author(s). Licensee IntechOpen. This chapter is distributed under the terms of the Creative Commons Attribution-NonCommercialShareAlike-3.0 License, which permits use, distribution and reproduction for non-commercial purposes, provided the original is properly cited and derivative works building on this content are distributed under the same license. 